\title{
CALCULATION AND MEASUREMENT OF RFID TAG CRITICAL FREQUENCY
}

This paper deals with undesirable phenomenon in inductively coupled RFID system, i. e. by fading out the amplitude modulation of carrier signal in RFID reader. It is caused by inaccurate tuning of RFID transponder resonant circuit. The phenomenon is described by mathematical model of the inductively coupled RFID system. The numerical and graphical results of mathematical modelling is then compared by measurement of resonant frequency of real (tuneable) RFID circuit on which the amplitude modulation fades out.

Keywords: RFID, tag, transponder, quality factor, critical frequency, mathematical model.

\section{Introduction}

Inductively coupled RFID (Radio Frequency Identification) systems [1] are being widely used for marking of goods and animals, in access control system, bus tickets and data acquisition systems etc. In these applications the reading range of RFID transponder is not extremely long and the quality factor $Q$ of the transponder resonant circuit is relatively small. Mostly $Q=15$ [2] for identification cards in accordance with the standard ISO 14443. The requirements for accurate tuning of the transponder resonant frequency are not generally critical.

If the required reading range of the RFID transponder must be essentially longer, for example, if underground engineering networks are marked by the RFID transponders [3], the reading range can be increased by increasing of transponder coil area together with increasing of transponder resonant circuit quality factor [4] Then inaccurate tuning of the transponder resonant frequency can make the data transfer from the transponder to the RFID reader impossible because the amplitude modulation of carrier signal fades out on the critical resonant frequency of the transponder.

\section{Mathematical model of inductively coupled RFID system}

The mathematical model was created to calculate system parameters in design process of RFID system, to analyse the influence of inaccurate tuning of reader and transponder resonant frequencies and to estimate maximum reachable reading range. The model goes out from the general schematic diagrams depicted in Figs. 1 and 2. Simplification of the model is given by the neglecting of
RFID transponder chip nonlinearity. These chips usually include a voltage limiter in the form of two anti-serially connected Zener diodes in parallel to the transponder resonant LC circuit which limit the voltage across the chip to values about $14-15 \mathrm{~V}$ peak to - peak. Therefore, this mathematical model is suitable to calculate RFID features when the limiter is not in operation, i. e. when the distance between RFID reader and transponder is relatively long.

\subsection{Dynamic model}

Let the transponder have two-state ( 0 and 1$)$ modulator and the modulation frequency is $1 / 64$ of carrier frequency, i. e. $f_{\text {Mod }}=$ $=f / 64$. We denote $R(t)=R_{P}$ if the modulator is in state 0 and $R(t)=R_{M}$ if the modulator is in state 1 . Let the modulator be controlled by the Data $(t)$ function according to equation (1). The resistance of RFID chip is then given by function (2). Let the excitation signal of the RFID reader be given by function (3).

$$
\begin{aligned}
& \operatorname{Data}(t)=\frac{\operatorname{Sign}\left(\sin \left(2 \pi \frac{f}{64} i\right)\right)+1}{2} \\
& R(t)=\operatorname{Data}(t) R_{P}+(1-\operatorname{Data}(t)) R_{M} \\
& u(t)=U \sin (2 \pi f t)
\end{aligned}
$$

The model in Fig. 1 can be described by a system of $2^{\text {nd }}$ order linear differential equations (4) which has not constant coefficients [5].

\footnotetext{
* Peter Vestenicky ${ }^{1}$, Martin Vestenicky ${ }^{2}$, Juraj Palecek ${ }^{3}$

${ }^{1}$ Department of Control and Information Systems, Faculty of Electrical Engineering, University of Zilina, Slovakia,

E-mail: peter.vestenicky@fel.uniza.sk

${ }^{2}$ Department of Telecommunications and Multimedia, Faculty of Electrical Engineering, University of Zilina, Slovakia

${ }^{3}$ Amicus SK s.r.o, Skalica, Slovakia
} 


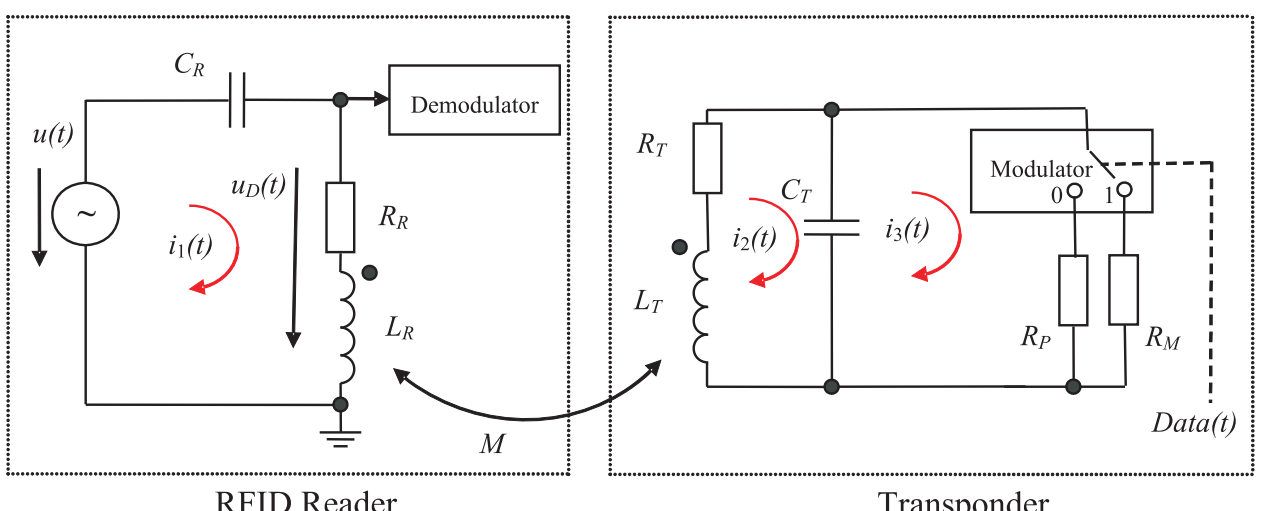

Fig. 1 Dynamic model of RFID system

$$
\begin{aligned}
& L_{R} \frac{d^{2} i_{1}(t)}{d t^{2}}+R_{R} \frac{d i_{1}(t)}{d t}+\frac{1}{C_{R}} i_{1}(t)-M \frac{d^{2} i_{2}(t)}{d t^{2}}=\frac{d u(t)}{d t} \\
& -M \frac{d^{2} i_{1}(t)}{d t^{2}}+L_{T} \frac{d^{2} i_{2}(t)}{d t^{2}}+R_{T} \frac{d i_{2}(t)}{d t}+ \\
& +\frac{1}{C_{T}} i_{2}(t)-\frac{1}{C_{T}} i_{3}(t)=0 \\
& \frac{1}{C_{T}} i_{2}(t)=R(t) \frac{d i_{3}(t)}{d t}-\frac{1}{C_{T}} i_{3}(t)=0
\end{aligned}
$$

\subsection{Static model}

This model considers only steady states of the RFID system modulation process. This is symbolically represented by selection of resistance value $R$ (see Fig. 2) from two elements $\left\{R_{P}, R_{M}\right\}$ i. e.

\begin{abstract}
$R=R_{P}$ when modulation switch is in the logical zero state and $R=R_{M}$ when modulation switch is in the logical one state. The resistance $R_{P}$ represents energy consumption of the RFID chip and the resistance $R_{M}$ represents the additional damping of resonant circuit when the actual data bit is in logical one state.
\end{abstract}

Going out from Fig. 2 we can create the next system of equations

$$
\begin{aligned}
& \left(R_{P}+j \omega L_{R}+\frac{1}{j \omega C_{R}}\right) I_{1}-j \omega M I_{2}=U \\
& -j \omega M I_{1}+\left(R_{T}+j \omega L_{T}+\frac{R}{1+j \omega R C_{T}}\right) I_{2}=0
\end{aligned}
$$

which can be solved by application of the Cramer's rule. Then the loop currents $I_{1}, I_{2}$ are given by (6) and (7).

$$
I_{1}=\frac{U\left(R_{T}+j \omega L_{T}+\frac{R}{1+j \omega R C_{T}}\right)}{\left(R_{R}+j \omega L_{R}+\frac{1}{j \omega C_{R}}\right)\left(R_{T}+j \omega L_{T}+\frac{R}{1+j \omega R C_{T}}\right)+\omega^{2} M^{2}}
$$

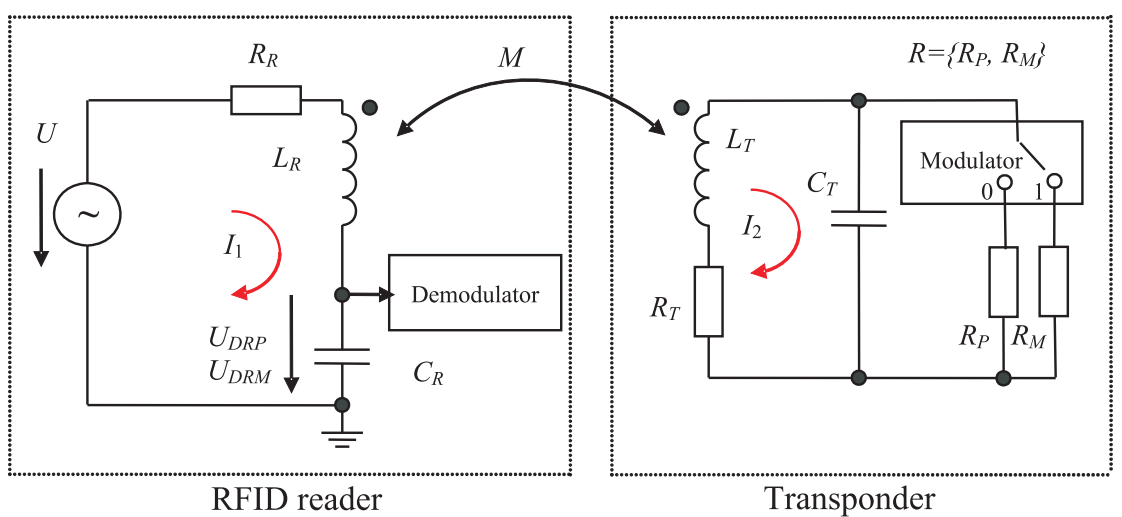

Fig. 2 Static model of RFID system 


$$
\begin{gathered}
I_{2}=\frac{j \omega M U}{\left(R_{R}+j \omega L_{R}+\frac{1}{j \omega C_{R}}\right)\left(R_{T}+j \omega L_{T}+\frac{R}{1+j \omega R C_{T}}\right)+\omega^{2} M^{2}} \\
U_{D R P}=\frac{U\left(R_{T}+j \omega L_{T}+\frac{R_{P}}{1+j \omega R_{P} C_{T}}\right)}{j \omega C_{R}\left(\left(R_{R}+j \omega L_{R}+\frac{1}{j \omega C_{R}}\right)\left(R_{T}+j \omega L_{T}+\frac{R_{P}}{1+j \omega R_{P} C_{T}}\right)+\omega^{2} k^{2} L_{R} L_{T}\right)} \\
U_{D R M}=\frac{U\left(R_{T}+j \omega L_{T}+\frac{R_{M}}{1+j \omega R_{M} C_{T}}\right)}{j \omega C_{R}\left(\left(R_{R}+j \omega L_{R}+\frac{1}{j \omega C_{R}}\right)\left(R_{T}+j \omega L_{T}+\frac{R_{M}}{1+j \omega R_{M} C_{T}}\right)+\omega^{2} k^{2} L_{R} L_{T}\right)} \\
\text { demodulator input in Fig. 2 is given by (8) } \quad R_{P}=R_{S}\left(\frac{U_{1}}{U_{2 P}}-1\right)
\end{gathered}
$$

for modulator switched to logical zero and by (9) for modulator switched to logical one. Note that $M$ is the mutual inductance of reader and transponder coils $L_{R}$ and $L_{T}, M=k \sqrt{L_{R} L_{T}}, k$ is coupling factor and $\omega=2 \pi f$ is angular frequency.

Going out from equations (8) and (9) we can calculate the modulation depth of amplitude modulated signal at the input of RFID reader demodulator:

$$
m_{A M}=\frac{\left|U_{D R P}\right|-\left|U_{D R M}\right|}{\left|U_{D R P}\right|+\left|U_{D R M}\right|}
$$

\section{Measurement of the RFID chip parameters}

To determine the resistances $R_{P}$ and $R_{M}$ a measurement of RFID transponder chip EM4100 (manufactured by EM Microelectronic - Marin SA, Switzerland) was performed according to Fig. 3.
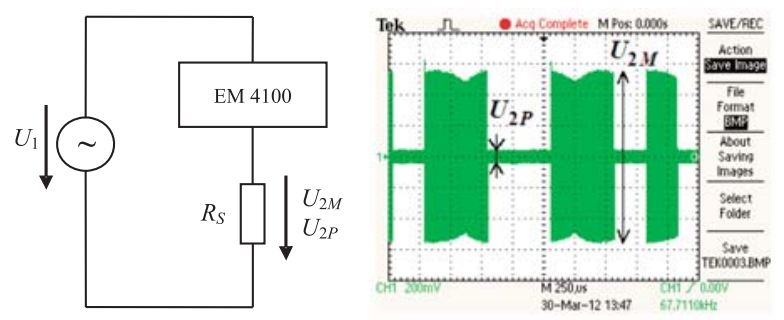

Fig. 3 Measurement of EM 4100 parameters

The equivalent resistances $R_{P}$ and $R_{M}$ are calculated from the measured voltages $U_{2 M}$ and $U_{2 P}$ (see Table 1 ) for $R_{S}=110 \Omega$ according to equations (11) and (12).

$$
R_{M}=R_{S}\left(\frac{U_{1}}{U_{2 M}}-1\right)
$$

For simplicity, the RFID chip EM4100 will be approximately modelled by the resistances $R_{P}=16 \mathrm{k} \Omega$ and $R_{M}=1.6 \mathrm{k} \Omega$ (Figs. 1 and 2).

Measurement of the equivalent EM 4100 resistances

Table 1

\begin{tabular}{|c|c|c|c|c|}
\hline$U_{1}[\mathrm{Vpp}]$ & $U_{2 P}[\mathrm{Vpp}]$ & $U_{2 M}[\mathrm{Vpp}]$ & $R_{P}[\mathrm{k} \Omega]$ & $R_{M}[\mathrm{k} \Omega]$ \\
\hline 5.0 & 0.032 & 0.045 & 17.08 & 12.11 \\
\hline 7.6 & 0.054 & 0.250 & 15.37 & 3.23 \\
\hline 10.0 & 0.068 & 0.640 & 16.07 & 1.61 \\
\hline 12.4 & 0.080 & 1.050 & 16.94 & 1.19 \\
\hline 14.0 & 0.094 & 1.440 & 16.27 & 0.96 \\
\hline 15.0 & 0.328 & 1.680 & 4.92 & 0.87 \\
\hline
\end{tabular}

\section{Graphical results}

The calculations according to equations (4) and (10) were performed for these parameters of RFID system:

- Voltage of signal generator $U=10 \mathrm{~V}$, frequency $f=125 \mathrm{kHz}$

- $C_{R}=1.621 \mathrm{nF}, L_{R}=1 \mathrm{mH}, R_{R}=15.7 \Omega$, i. e. reader resonant frequency is $125 \mathrm{kHz}$, quality factor of $L_{R} C_{R}$ tuned circuit is $Q_{R}=50$

- $C_{T}=1.621 \mathrm{nF}$ (or variable if the resonant frequency of transponder $f_{T}$ is variable), $L_{T}=1 \mathrm{mH}, R_{T}=7.85 \Omega$

- $R_{P}=16 \mathrm{k} \Omega, R_{M}=1.6 \mathrm{k} \Omega$ (chapter 3)

- $k=0.01$ or variable

\subsection{Dynamic model}

By numerical solving the system of differential equations (4) for parameters given above the time responses of signals at the 
input of reader demodulator were obtained. These time responses are shown in Fig. 4 for nominal resonant frequency of transponder $\left(f_{T}=125 \mathrm{kHz}\right)$ and in Fig. 5 for detuned transponder $\left(f_{T}=136\right.$ $\mathrm{kHz}$ ). In case of detuned transponder the amplitude modulation of signal fades out and the transponder becomes unreadable.

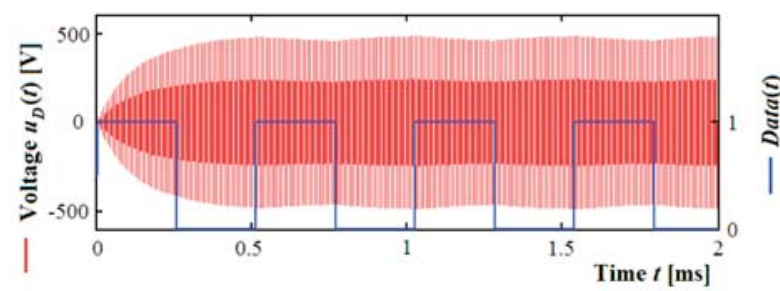

Fig. 4 Voltage at demodulator input as a function of time, transponder resonant frequency $f_{T}=125 \mathrm{kHz}$

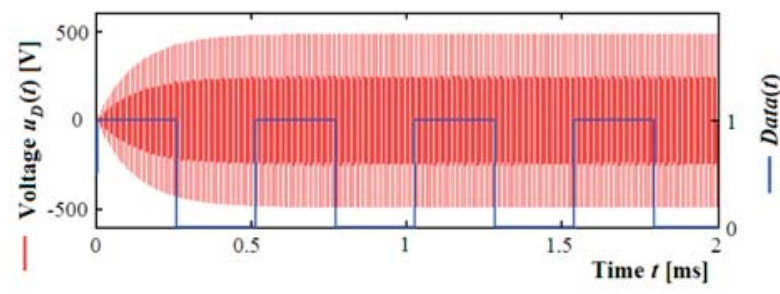

Fig. 5 Voltage at demodulator input as a function of time, transponder resonant frequency $f_{T}=136 \mathrm{kHz}$

\subsection{Static model}

The fade of amplitude modulation in RFID reader under condition of transponder detuning to the critical resonant frequency is evident from the three dimensional graph of function (10) which is shown in Fig. 6.

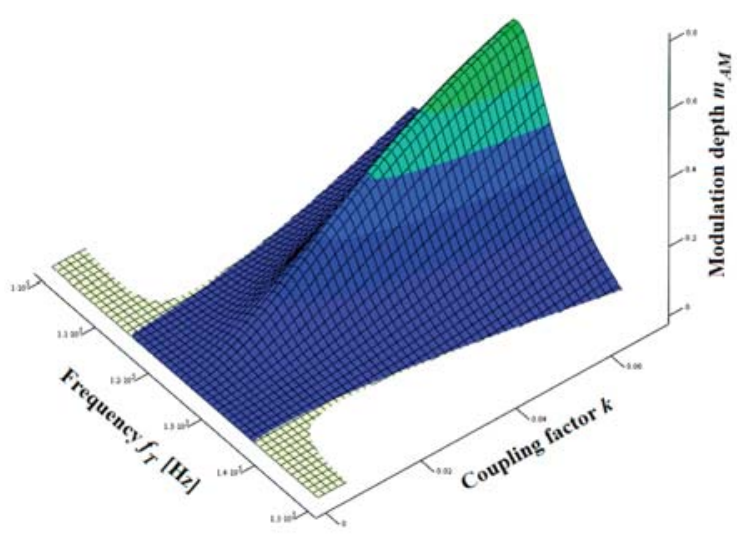

Fig. 6 Modulation depth $m_{A M}$ as a function of coupling factor $k$ and transponder resonant frequency $f_{T}$
By substituting (16) into (8) and (9) we can calculate the dependence of AM modulation depth $m_{A M}$ (10) on distance $x$ between the RFID transponder and the RFID reader and on the transponder resonant frequency $f_{T}$. The $3 \mathrm{D}$ graph is shown in Fig. 7.

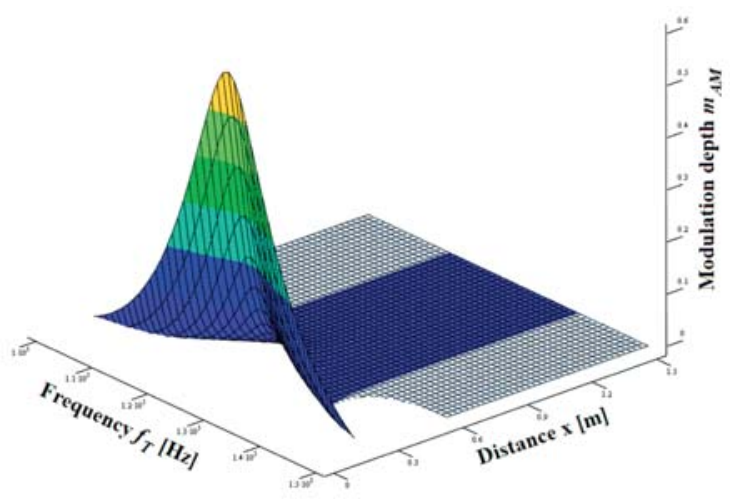

Fig. 7 Modulation depth $m_{A M}$ as a function of distance $x$ and transponder resonant frequency $f_{T}$

Similar, if we substitute (13) into (8), (9) and then (10) we can calculate the dependence of modulation depth on the resonant frequency $f_{R}$ of the reader LC circuit and coupling factor $k$ or distance $x$ respectively, see Fig. 8 and Fig. 9.

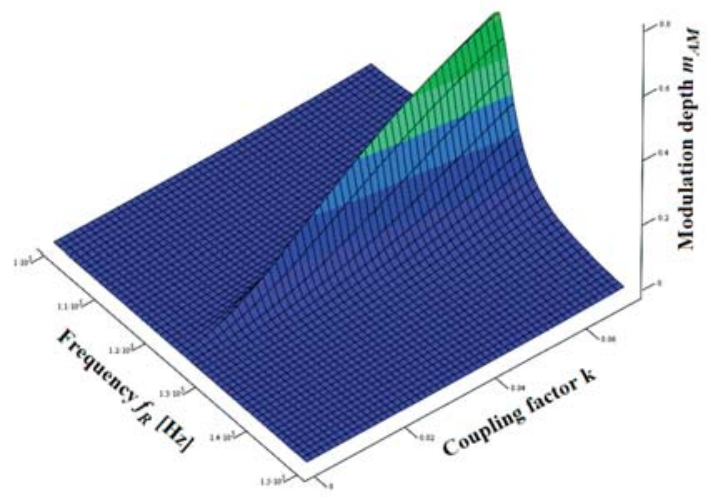

Fig. 8 Modulation depth $m_{A M}$ as a function of coupling factor $k$ and resonant frequency $f_{R}$ of reader antenna

From the series of $3 \mathrm{D}$ graphs it is evident that detuning of transponder causes its unreadability due to fall of amplitude modulation, i. e. certain critical frequency exists which is dependent on distance (or coupling factor) and on other parameters of RFID system especially on quality factors of tuned LC circuits. The detuning of the reader antenna LC circuit is not so critical because the surfaces of 3D graphs in Figs. 8 and 9 do not cross zero plane of modulation depth.

The critical frequency $f_{C}$ can be calculated from equation (14) substituting (15) into (8) and (9). The equation (14) has two solutions $f_{C_{-} H I G H}, f_{C_{-} \text {LOW }}$ whose dependency on coupling factor $k$ is 


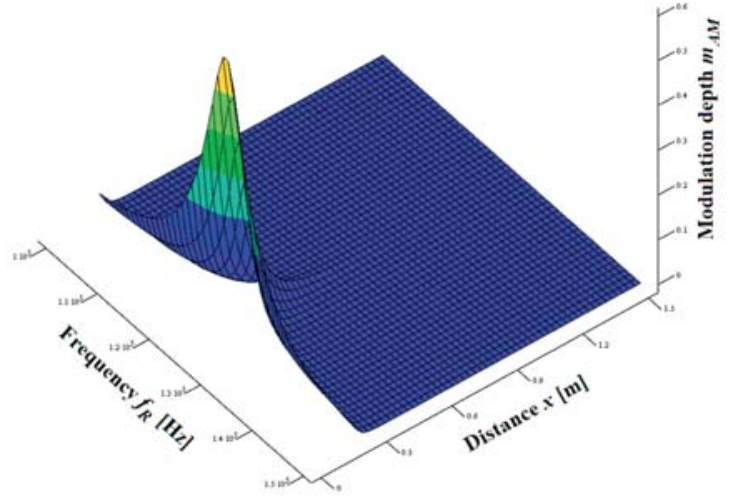

Fig. 9 Modulation depth $m_{A M}$ as a function of distance $x$ and resonant frequency $f_{R}$ of reader antenna

shown in Fig. 10. After substituting (16) into (8) and (9) we can obtain dependency of critical frequencies on distance $x$ between reader and transponder coils. It is shown in Fig. 11.

The equation (16) describes coupling factor of two circular coils as a function of their radiuses $r_{R}, r_{T}$, angle $\theta$, and distance $x$ [6]. The calculations of graphs in Figs. 7, 9 and 11 were performed for $r_{R}=0.1 \mathrm{~m}, r_{R}=0.1 \mathrm{~m}$, and $\theta=0^{\circ}$, i. e. both coils are parallel.

$$
\begin{aligned}
& C_{R}=\frac{1}{\left(2 \pi f_{R}\right)^{2} L_{R}} \\
& \left|U_{D R M}\right|-\left|U_{D R P}\right|=0 \\
& C_{T}=\frac{1}{\left(2 \pi f_{C}\right)^{2} L_{T}} \\
& k=\frac{r_{R}^{2} \cdot r_{T}^{2} \cdot \cos \theta}{\sqrt{r_{R} \cdot r_{T}} \cdot\left(r_{R}^{2}+x^{2}\right)^{\frac{3}{2}}}
\end{aligned}
$$

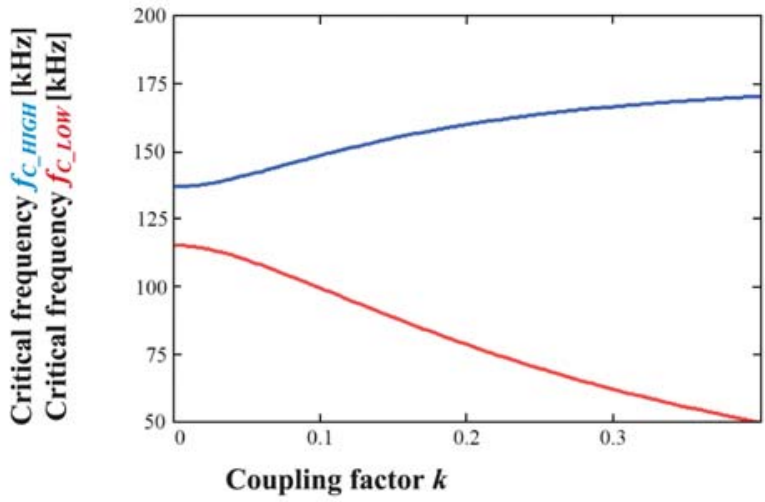

Fig. 10 Transponder critical frequencies as a function of coupling factor $k$

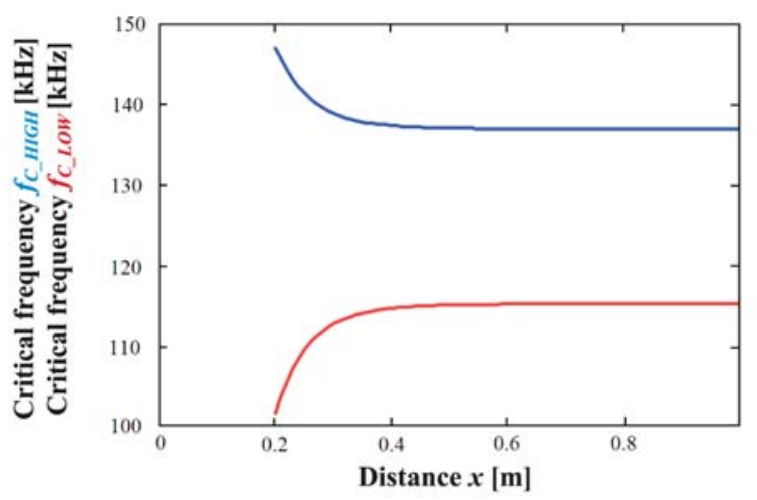

Fig. 11 Transponder critical frequencies as a function of distance $x$ between coils $L_{R}$ and $L_{T}$

\section{Comparison of calculated and measured critical frequencies}

To compare the results of mathematical model described in chapters 2 and 4 with real properties of inductively coupled RFID system the measurement of critical frequencies and their dependency on distance between transponder and reader was performed. The measured circuits were arranged according to Fig. 1 where transponder capacitor $C_{T}$ was replaced by parallel connection of fixed and variable capacitor to enable the tuning of transponder resonant frequency. The critical frequencies were found when the amplitude modulation became extinct. The modulator and its resistances $R_{P}$ and $R_{M}$ were replaced by RFID chip EM 4100 (chapter 3).

Measured and calculated critical frequencies

Table 2

\begin{tabular}{|c|c|c|c|c|}
\hline \multirow{2}{*}{$\begin{array}{c}\text { Distance } x \\
{[\mathrm{~m}]}\end{array}$} & \multicolumn{2}{|c|}{$\begin{array}{c}\text { Measured critical } \\
\text { frequency }\end{array}$} & \multicolumn{2}{c|}{$\begin{array}{c}\text { Calculated critical } \\
\text { frequency }\end{array}$} \\
\cline { 2 - 5 } & $\begin{array}{c}f_{\text {C_LWW }}[\mathrm{kHz}] \\
f_{\text {C_HIGH }}[\mathrm{kHz}]\end{array}$ & $\begin{array}{c}\text { fC_LOW } \\
{[\mathrm{kHz}]}\end{array}$ & $\begin{array}{c}\text { fC_HIGH } \\
{[\mathrm{kHz}]}\end{array}$ \\
\hline 0.20 & 102.12 & 199.22 & 94.19 & 139.15 \\
\hline 0.25 & 103.84 & 154.39 & 102.47 & 133.35 \\
\hline 0.30 & 107.16 & 138.63 & 106.01 & 130.61 \\
\hline 0.35 & 109.51 & 130.39 & 107.50 & 129.41 \\
\hline 0.40 & 111.76 & 126.08 & 108.15 & 128.88 \\
\hline 0.45 & 113.25 & 123.53 & 108.44 & 128.63 \\
\hline 0.50 & 113.90 & 121.96 & 108.59 & 128.51 \\
\hline
\end{tabular}

The results of calculations according to equation (14) and measurements are listed in Table 2 and displayed in Fig. 12. The nominal working frequency used in experiment and calculations has nonstandard value $117.7 \mathrm{kHz}$ which is given by used inductor $L_{R}$ and capacitor $C_{R}$. Other parameters were set as follows: 
- Voltage of signal generator $U=5 \mathrm{~V}$, frequency $f=117.7 \mathrm{kHz}$

- $C_{R}=2.4 \mathrm{nF}, L_{R}=760 \mu \mathrm{H}$, i. e. reader resonant frequency is $f_{R}=117.7 \mathrm{kHz}$, measured quality factor of $L_{R} C_{R}$ tuned circuit is $Q_{R}=62$, then equivalent resistance $R_{R}=9.08 \Omega$

- $C_{T}$ is variable i. e. transponder resonant frequency $f_{T}$ is variable), $L_{T}=1.04 \mathrm{mH}, R_{T}=8.37 \Omega$

- $R_{P}=16 \mathrm{k} \Omega, R_{M}=1.6 \mathrm{k} \Omega$ (chapter 3$)$

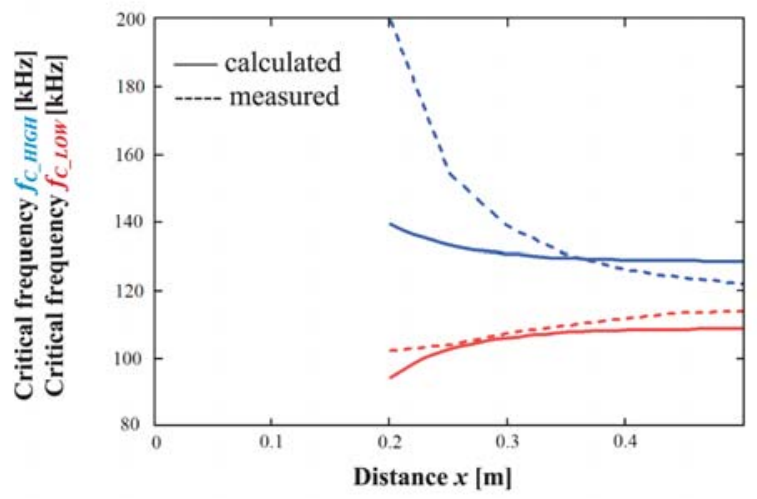

Fig. 12 Comparison of calculated and measured transponder critical frequencies

\section{Conclusion}

The method of RFID transponder critical frequency calculation can be useful at the design of transponder LC circuit. Espe- cially, it can be useful to determine the acceptable manufacturing tolerances of transponder resonant frequency. Moreover, the required bandwidth of modulated signal from transponder must be considered. Note that the required bandwidth is about $4 \mathrm{kHz}$ for the used RFID chip EM 4100 (with Manchester coding and with data transfer rate $1 / 64$ of carrier frequency $125 \mathrm{kHz}$ ).

The used mathematical model is simplified by neglecting the nonlinearity of transponder (RFID chip) modulation circuits, which is evident from Table 1. Therefore, the results of critical frequency calculations in Figs. 10 and 11 must be considered as informative and their validity must be limited to the lower values of the coupling factor or higher values of the distance between the transponder and reader. This limitation of linear mathematical model is evident by comparison of calculated and measured results in Fig. 12. Moreover, high difference between measured and calculated critical frequencies $f_{C \text { HIGH }}$ in Fig. 12 (upper curves) is probably caused by external overvoltage suppressors connected to the used RFID chip, because capacity of the suppressor is not constant and is dependent on the applied voltage. At higher resonant frequencies the capacity of overvoltage suppressors becomes dominant compared to external capacitor $C_{T}$. This limitation will be subject to further improvement of the mathematical model.

\section{Acknowledgment}

This publication is the result of the project implementation: "Centre of excellence for systems and services of intelligent transport II”, ITMS 26220120050 supported by the Research \& Development Operational Programme funded by the ERDF. "Podporujeme vyskumne aktivity na Slovensku / Projekt je spolufinancovany zo zdrojov EU"

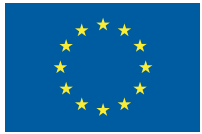

Európska únia
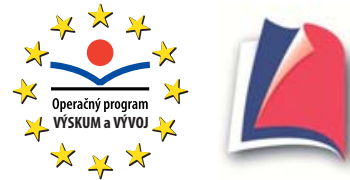

Agentúra

Ministerstva školstva, vedy, výskumu a športu SR pre štrukturálne fondy EÚ

\section{References}

[1] FINKENZELLER, K.: RFID Handbook. Fundamentals and Applications in Contactless Smart Cards and Identification. $2^{\text {nd }}$ edition. John Wiley and Sons, Chichester, 2003. ISBN 978-0-470-84402

[2] ROMERO, H. P., REMLEY, K. A., WILliAMS, D. F., CHIH-MING, W., BROWN, T. X.: Identifying RF Identification Cards From Measurements of Resonance and Carrier Harmonics. IEEE Transactions on Microwave Theory and Techniques, vol. 58, No. 7, July 2010, pp. 1758-1765. ISSN 0018-9480

[3] VESTENICKY, P.: Solution of Some Technical Problems in Marker and Marker Locator Development. Communications - Scientific Letters of the University of Zilina, vol. 6, No. 4, 2004, pp. 103-106. ISSN 1335-4205

[4] VESTENICKY, P.: Increasing of RFID System Read Range. Advances in Electrical and Electronic Engineering, vol. 5, No. 1-2, 2006, pp. 171-173. ISSN 1336-1376

[5] RUZICKOVA, M.: Discrete and Differential Equations in Applied Mathematics. Communications - Scientific Letters of the University of Zilina, vol. 10, No. 2, 2008, pp. 72-78. ISSN 1335-4205

[6] GEHRING, U., ROZ, T.: RFID Made Easy. EM Microelectronic-Marin SA, Marin, 2000. 